\title{
Patterns of health care use in a high-cost inpatient population in Ottawa, Ontario: a retrospective observational study
}

\author{
Paul E. Ronksley PhD, Jennifer A. McKay BSc, Daniel M. Kobewka MD, Sunita Mulpuru MD, \\ Alan J. Forster MD MSc
}

\section{Abstract}

Background: A small proportion of patients account for the majority of health care spending. We used detailed clinical and administrative data to explore clinical characteristics, patterns of health care use and changes in cost profiles over time among high-cost inpatients in an acute tertiary care hospital in Ottawa, Ontario.

Methods: We identified all people who had 1 or more inpatient admissions to The Ottawa Hospital between Apr. 1, 2009, and Mar. 31, 2012. We calculated the direct inpatient costs using case-costing information to categorize patients into persistently highcost, episodic high-cost and non-high-cost groups. Within each group, we used discharge abstracts to measure encounter-level characteristics and patterns of inpatient health care use over time. We also developed transition matrices to explore how inpatient costing states changed over time.

Results: During the study period, 100178 patients had 132996 hospital admissions. Hospital spending was often limited to a single year for most of the patients $(90.2 \%)$, with only a small proportion $(7.4 \%)$ of patients remaining in the high-cost group in the subsequent year. Patients in the persistently $(n=236)$ and episodic $(n=5062)$ high-cost groups were often older, had medically complex conditions and generated most of the costs from nursing care and intensive care. Compared with patients in the other cost groups, those in the persistently high-cost group were more likely to have multiple readmissions (43.4\%) and multiple placements in an alternate level of care (19.0\%) and were high users of health care services outside of the hospital setting.

Interpretation: Hospital spending was often limited to a single year for most patients, and only a small proportion of patients remained in the high-cost group in the subsequent year. These persistently high-cost patients had medically complex conditions and often required expensive care. A greater understanding of the circumstances that result in persistent hospital spending remains an area for future work, including an exploration of the potential barriers impeding efficient transition out of acute care for high-risk patients.

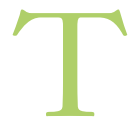
he cost of providing health care services to entire populations is high. In Canada, total health care expenditures have doubled in the past decade and were forecasted to exceed $\$ 200$ billion by $2014 .{ }^{1}$ The fact that actual spending is unevenly distributed across individuals in the population compounds the issue and places additional pressure on our system to derive greater value from the resources devoted to health care. It has been estimated that the top $5 \%-10 \%$ of health care users account for more than $50 \%$ of health care utilization and costs..$^{2-7}$ Furthermore, about $40 \%$ of all health spending is for hospital care, which is similarly skewed toward the so-called "high user."

It is important to assess hospital spending in this high-user population to inform cost-management strategies. Accurately identifying the small group of hospital patients who remain highcost users in subsequent years is also important, because they represent patients for whom case management and coordinated care could be focused, with a potentially large benefit. Prior work has aimed to identify and predict individuals at greatest risk of future high costs. However, it has proven difficult given the large random component to individual health care costs, with patients moving in and out of high-cost states over time. ${ }^{8-14}$ Studies have also attempted to characterize this heterogeneous group of "persistently high-cost" patients. ${ }^{3,6,15-17}$ Many have focused on

Competing interests: None declared.

This article has been peer reviewed.

Correspondence to: Paul Ronksley, peronksı@ucalgary.ca

CMAJ Open 2015. DOI:10.9778/cmajo.20140049 
patients with specific chronic medical conditions, older populations, or certain insurance beneficiaries within the United States, which limits the usefulness and generalizability of their findings to an entire health care system. Furthermore, there is limited information on how costs accumulate over time among high-cost inpatients in a Canadian setting and how these patients engage with other aspects of the health care system.

Many hospitals and health systems are faced with increasing financial pressures. A greater understanding of the patterns of health care use and how costs accumulate over time among high users may help improve predictive modelling and targeting of patients where medical management could mitigate future health costs. We used detailed clinical and administrative data to explore patterns of hospital use, transitions between cost states and clinical characteristics of different cost groups in a Canadian acute tertiary care hospital in Ottawa, Ontario.

\section{Methods}

\section{Data sources and study population}

We conducted a retrospective observational study using The Ottawa Hospital Data Warehouse. The Ottawa Hospital is a tertiary care teaching facility with 2 acute care campuses containing 1100 beds. It is the largest referral centre for a population of 1.1 million people in eastern Ontario. The Data Warehouse is a relational database that has been widely used in previous research and contains information from several of the hospital's information systems, including the patient registration system, clinical data repository, case-costing system and patient abstracts for multiple encounter types. Extensive assessments of data quality were performed during the development of the data warehouse and are executed routinely as new data are included. Quality-assurance initiatives to ensure completeness and accuracy of the data are also conducted regularly. Within these data sources, we identified all individuals (regardless of age) who had 1 or more inpatient hospital admissions between Apr. 1, 2009, and Mar. 31, 2012. We excluded hospital events with admission dates that fell outside of the defined timeframe.

\section{Identification of cost states}

We identified direct costs for each inpatient encounter within the case-costing system of the Ottawa Hospital Data Warehouse. The case-costing system links financial, clinical and patient activity information stored within information systems of the data warehouse to define "intermediate products" (e.g., nursing time, medications, laboratory tests). Direct and indirect costs for each intermediate product used during an encounter are then summed for each patient. The Ottawa Hospital uses a standardized case-costing methodology that was developed by the Ontario Case Costing Initiative ${ }^{18}$ and is based on the Canadian Institute for Health Information Management Information Systems guidelines. ${ }^{19}$ We summed costs for patients who had multiple hospital admissions within each fiscal year of data.

Using the distribution of cumulative direct costs for each year, we categorized patients into 3 cost groups: persistently high cost (patients whose costs were in the top $5 \%$ in 2 or more of the study years), episodic high cost (those whose costs who were in the top $5 \%$ in only 1 year) and non-high cost (those whose costs were in the bottom 95\%, including those who had no events in a fiscal year).

\section{Data collection}

We used information from the patient registry file and hospital abstracts to measure demographic and clinical characteristics for each cost group. Using the first (index) hospital admission for each patient, we measured age, sex, marital status and comorbidity. We used data from hospital discharge abstracts to determine the number of hospital encounters during the study period and to identify specific encounter-level characteristics, including admission and discharge dates, length of stay (days in acute care, alternate level of care and intensive care unit [ICU]), in-hospital deaths, all-cause readmission within 30 days and discharge disposition of the last hospital admission. We determined comorbidity using the Elixhauser Comorbidity Index and derived Elixhauser comorbidity scores. ${ }^{20,21}$ Coded information within the discharge abstracts database is based on the ICD-10-CA (International Statistical Classification of Diseases and Related Health Problems, 10th revision, Canada).

We extracted data on additional measures of health care utilization (outpatient, emergency department, surgical and medical daycare visits) from the Ottawa Hospital Data Warehouse. We measured the number of outpatient, emergency department, surgical and medical daycare visits that occurred in the hospital in the year before and the year after the index admission for each patient.

We captured overall costing estimates (3-yr cumulative costs) and in-hospital resource utilization using individual direct cost details within the case-costing system. These include 11 resource-specific direct cost categories adapted from the Ontario Quality-Based Procedures Groupings (e.g., nursing, laboratory, pharmacy and operating room costs; see Appendix 1, available at www.cmajopen.ca/content/3/1/E111/ suppl/DC1). We calculated the relative proportion of the total cost attributable to each resource category by summing category costs and dividing them by the total direct hospital cost for the respective high- and non-high-cost group.

\section{Statistical analysis}

We describe patient characteristics and health care use using proportions, means \pm standard deviations, and medians and interquartile ranges (IQRs) where appropriate. We compared measures across the 3 cost groups. The concentration of direct inpatient spending was calculated across the high and non-high cost groups and reported as a percentage of the total direct inpatient spending and as the average direct cost per patient.

To explore how inpatient costing states changed over time, we developed a transition matrix to indicate the probability of an individual moving from one cost state to another. For each patient, we calculated hospital spending for each fiscal year using the admission date of each inpatient encounter to assign costs to the fiscal year. Four cost states were examined in this 
analysis: the top $5 \%$ of costs, the top $5 \%-10 \%$ of costs, the bottom $90 \%$ of costs and no hospital costs within a fiscal year. In each of the 4 states, we grouped patients according to whether they were alive or died in the fiscal year. Within the matrix, rows represent the current cost state and columns represent the cost state at the end of the period of interest. Initially, separate transition matrices were generated for each year. Using information from these matrices, an average transition matrix was computed and represents the probability of changing cost states within any 1-year period. We also calculated 2- and 5-year matrices to assess transition probabilities over longer periods. This methodology has been used previously in health research ${ }^{22}$ and identifies patients at risk of remaining high cost or changing to a higher cost state over time.

We conducted all analyses using STATA 13.0 statistical software (Statacorp).

\section{Ethics approval}

The study was approved by the Ottawa Health Science Network Research Ethics Board, which granted waiver of patient consent.

\section{Results}

\section{Clinical characteristics}

During the 3-year study period, a total of 100178 patients had 132996 hospital admissions. Most of the patients (90.2\%) had admissions limited to a single year. Within each year, cumulative direct costs of $\$ 30000$ or more defined the top $5 \%$ of costs. Based on this cut-off, $236(0.2 \%)$ of the patients were in the persistently high-cost group, 5062 (5.1\%) in the episodic high-cost group and 94880 (94.7\%) in the nonhigh-cost group. In general, patients in the 2 high-cost groups were more likely than those in the non-high-cost group to be male, to be older and to have higher levels of comorbidity (Table 1).

\section{Resource utilization}

Patients in the 2 high-cost groups were most likely to have multiple hospital encounters during the study period (Table 2). The median total days spent in hospital, in ICU and in an alternate level of care were higher in the persistently high-cost group than in the other groups. In the persistently high-cost group, $28.8 \%$ of the patients had 2 or more ICU admissions, and $19.0 \%$ had 2 or more admissions to an alternate level of care. All-cause readmission within 30 days and in-hospital death were more common in the 2 high-cost groups than in the non-high-cost group. Among patients in the persistently high-cost group, $43.4 \%$ had multiple readmissions within 30 days, and $25.0 \%$ died in hospital. Transfer to long-term care was the most common discharge disposition of the final admission in the high-cost groups $(26.7 \%$ of patients in persistently and $24.0 \%$ in episodic high-cost group), followed by inhospital death $(25.0 \%$ and $22.7 \%$, respectively). In the nonhigh-cost group, the most common disposition was discharge home $(78.8 \%)$, with $5.6 \%$ being transferred to long-term care and $4.0 \%$ dying in hospital.
Over the study period, the study cohort generated more than $\$ 936$ million in direct inpatient spending, with a median direct cost of \$3598 (IQR \$1485-\$8864) per patient (Table 2). Patients in the persistently high-cost group accounted for $0.2 \%$ of the cohort and $3.8 \%$ of the total inpatient spending. The median direct cost per patient in this high-cost group was \$136 558 (IQR \$98 514-\$174 328). Nursing costs and ICU resources represented the largest components of total spending in both of the high-cost groups. Proportional spending on pharmacy and health professional services was higher in the high-cost groups than in the non-high-cost group, whereas operating room spending was higher in the latter group than in the high-cost groups.

Analysis of additional health care utilization in the year before and the year after the index admission showed that the high-cost groups used more outpatient physician and emergency department services compared with the non-high-cost group (Table 3). Although use in both periods was greatest in the persistently high-cost group, resource utilization for outpatient physician and emergency department visits in the 2 high-cost groups appeared to double in the year after the index admission.

The probability of changing cost states within a 1-year period is shown in Table 4. Among patients who were in the top $5 \%$ or $5 \%-10 \%$ cost status at the beginning of the year, most $(70.9 \%$ and $76.5 \%$, respectively) had no hospital admissions in the following year. Those who did have hospital encounters during the year were more likely to move to a lower cost status than to stay in the same cost status or move to a higher one. About $7.5 \%$ of patients in the highest cost group remained at the top status at the end of the year $(5.7 \%$ alive, $1.7 \%$ dead). Although most patients did not have subsequent admissions during the 1-year period, a larger proportion of patients were likely to be readmitted over the 2- and 5-year periods (see Appendices 2 and 3, available at www.cmajopen. $\mathrm{ca} /$ content/3/1/E111/suppl/DC1). Among patients who began in the top $5 \%$ cost status, $35.2 \%$ and $26.9 \%$ moved to the lower $90 \%$ cost status after 2 and 5 years respectively. Only a small proportion of patients remained in the top $5 \%$ after 2 years $(2.2 \%)$ and 5 years $(2.6 \%)$.

\section{Interpretation}

In this cohort of patients in a Canadian acute tertiary care hospital, we explored the patterns of health care use and how cost profiles changed over time. Hospital spending was often limited to a single year for most of the patients, and only a small proportion of patients remained in the high-cost group in subsequent years. These persistently high-cost patients were more likely to have multiple ICU admissions, placements to an alternate level of care and readmissions within 30 days, and they were high users of health care services outside of the hospital setting. Although they made up a small portion of the total inpatient population at any time, they consumed a disproportionate amount of resources and represented a group where efforts to coordinate care could result in substantial health care savings. 
Table 1: Characteristics of patients at index hospital admission, by cost status*

\begin{tabular}{|c|c|c|c|c|}
\hline \multirow[b]{2}{*}{ Characteristic } & \multicolumn{4}{|c|}{ Cost status; $\%$ of patients $\dagger$} \\
\hline & $\begin{array}{c}\text { All } \\
n=100178\end{array}$ & $\begin{array}{l}\text { Persistently high cost } \\
\qquad n=236\end{array}$ & $\begin{array}{l}\text { Episodic high cost } \\
\quad n=5062\end{array}$ & $\begin{array}{c}\text { Non-high cost } \\
n=94880\end{array}$ \\
\hline Age, yr, median (IQR) & $43(24-66)$ & $60(49-73)$ & $66(51-78)$ & $40(23-65)$ \\
\hline \multicolumn{5}{|l|}{ Age group, yr } \\
\hline$\leq 18$ & 21.1 & 0.9 & 6.6 & 21.9 \\
\hline $19-45$ & 31.1 & 18.2 & 12.2 & 32.2 \\
\hline $46-69$ & 26.3 & 51.7 & 38.7 & 25.6 \\
\hline $70-79$ & 10.8 & 17.4 & 21.6 & 10.2 \\
\hline$\geq 80$ & 10.7 & 11.9 & 20.9 & 10.1 \\
\hline Sex, male & 39.6 & 54.7 & 52.6 & 38.9 \\
\hline \multicolumn{5}{|l|}{ Marital status } \\
\hline Married or common law & 50.1 & 56.8 & 52.0 & 49.9 \\
\hline Single & 33.5 & 19.9 & 22.7 & 34.1 \\
\hline Separated, divorced or widowed & 11.9 & 21.6 & 22.1 & 11.3 \\
\hline Unknown & 4.6 & 1.7 & 3.2 & 4.6 \\
\hline \multicolumn{5}{|l|}{ Comorbid condition (Elixhauser index) } \\
\hline Congestive heart failure & 3.4 & 12.3 & 10.0 & 3.1 \\
\hline Cardiac arrhythmias & 5.1 & 12.3 & 14.3 & 4.6 \\
\hline Valvular disease & 0.9 & 1.3 & 2.0 & 0.8 \\
\hline Pulmonary circulation disorder & 1.0 & 2.1 & 3.0 & 0.9 \\
\hline Peripheral vascular disorder & 2.7 & 13.6 & 8.6 & 2.4 \\
\hline Hypertension (uncomplicated) & 11.7 & 31.8 & 29.1 & 10.7 \\
\hline Hypertension (with complications) & 0.3 & 2.5 & 1.0 & 0.2 \\
\hline Paralysis & 1.1 & 4.2 & 4.5 & 0.9 \\
\hline Neurodegenerative disorder & 2.9 & 11.9 & 7.9 & 2.6 \\
\hline Chronic obstructive pulmonary disease & 4.8 & 13.1 & 11.0 & 4.4 \\
\hline Diabetes (uncomplicated) & 7.8 & 24.6 & 15.5 & 7.4 \\
\hline Diabetes (with complications) & 6.9 & 26.3 & 20.9 & 6.1 \\
\hline Hypothyroidism & 1.2 & 2.5 & 2.1 & 1.1 \\
\hline Renal failure & 2.4 & 12.3 & 8.0 & 2.1 \\
\hline Liver disease & 1.2 & 3.8 & 3.8 & 1.1 \\
\hline Peptic ulcer disease, no bleeding & 0.5 & 3.0 & 1.2 & 0.4 \\
\hline AIDS/HIV & 0.2 & 0 & 0.8 & 0.2 \\
\hline Lymphoma & 1.1 & 5.1 & 4.7 & 0.9 \\
\hline Metastatic cancer & 4.4 & 4.7 & 8.1 & 4.2 \\
\hline Solid tumour without metastasis & 10.7 & 14.0 & 18.9 & 10.3 \\
\hline Rheumatoid arthritis & 0.7 & 1.7 & 2.1 & 0.6 \\
\hline Coagulopathy & 1.1 & 3.8 & 3.5 & 1.0 \\
\hline Obesity & 1.5 & 3.0 & 1.8 & 1.5 \\
\hline Weight loss & 1.0 & 7.6 & 3.6 & 0.9 \\
\hline Fluid and electrolyte disorder & 3.9 & 14.0 & 10.8 & 3.5 \\
\hline Blood-loss anemia & 0.3 & 0 & 0.6 & 0.3 \\
\hline Deficiency anemia & 1.0 & 3.4 & 2.7 & 0.9 \\
\hline Alcohol abuse & 1.8 & 6.8 & 4.4 & 1.7 \\
\hline Drug abuse & 1.0 & 4.2 & 1.5 & 1.0 \\
\hline Psychosis & 0.8 & 3.0 & 1.7 & 0.8 \\
\hline Depression & 2.0 & 4.7 & 3.2 & 2.0 \\
\hline Elixhauser comorbidity score, median (IQR) & $0(0-4)$ & $5(0-11)$ & $5(0-11)$ & $0(0-3)$ \\
\hline
\end{tabular}


Table 2: Encounter characteristics, health outcomes and spending, by cost status*

\begin{tabular}{|c|c|c|c|c|}
\hline \multirow[b]{2}{*}{ Variable } & \multicolumn{4}{|c|}{ Cost status; $\%$ of patients $\dagger$} \\
\hline & $\begin{array}{c}\text { All } \\
n=100178\end{array}$ & $\begin{array}{l}\text { Persistently high cost } \\
\qquad n=236\end{array}$ & $\begin{array}{l}\text { Episodic high cost } \\
\qquad n=5062\end{array}$ & $\begin{array}{l}\text { Non-high cost } \\
n=94880\end{array}$ \\
\hline Total no. of hospital encounters & 132996 & 1528 & 11730 & 119738 \\
\hline No. of hospital admissions, median (IQR) [range] & $1(1-1)[1-41]$ & $5(4-8)[2-41]$ & $2(1-3)[1-17]$ & $1(1-1)[1-18]$ \\
\hline Total days in hospital, median (IQR) & $3(2-8)$ & $128(98-181)$ & $53(34-79)$ & $3(2-6)$ \\
\hline \multicolumn{5}{|l|}{ No. of admissions to ICU } \\
\hline 0 & 90.0 & 39.0 & 49.6 & 92.3 \\
\hline 1 & 9.5 & 32.2 & 45.5 & 7.5 \\
\hline$\geq 2$ & 0.5 & 28.8 & 4.9 & 0.2 \\
\hline Total days in ICU, $\ddagger$ median (IQR) & $4(1-10)$ & $16(9-30)$ & $14(8-25)$ & $2(1-6)$ \\
\hline$\%$ of total hospital days spent in ICU, median (IQR) & $0(0-0)$ & $5.9(0-17.3)$ & $1.7(0-41.5)$ & $0(0-0)$ \\
\hline \multicolumn{5}{|l|}{ No. of admissions to alternate level of care } \\
\hline 0 & 95.5 & 54.7 & 67.2 & 97.2 \\
\hline 1 & 4.1 & 26.3 & 29.3 & 2.7 \\
\hline$\geq 2$ & 0.4 & 19.0 & 3.5 & 0.1 \\
\hline Total days in alternate level of care,§ median (IQR) & $14(6-32)$ & $32(11-84)$ & $29(11-61)$ & $9(4-20)$ \\
\hline $\begin{array}{l}\% \text { of total hospital days spent in alternate level of } \\
\text { care setting, median (IQR) }\end{array}$ & $0(0-0)$ & $0(0-21.4)$ & $0(0-19.3)$ & $0(0-0)$ \\
\hline \multicolumn{5}{|l|}{ No. of all-cause readmissions $\leq 30 \mathrm{~d} \eta$} \\
\hline 0 & 92.8 & 30.9 & 65.4 & 94.2 \\
\hline 1 & 5.7 & 25.7 & 21.9 & 4.9 \\
\hline$\geq 2$ & 1.5 & 43.4 & 12.7 & 0.9 \\
\hline In-hospital death & 5.0 & 25.0 & 22.7 & 4.0 \\
\hline \multicolumn{5}{|l|}{ Discharge disposition (last admission) } \\
\hline Home & 75.7 & 16.5 & 22.3 & 78.8 \\
\hline Home with support services & 9.0 & 22.5 & 20.4 & 8.4 \\
\hline In-hospital death & 5.0 & 25.0 & 22.7 & 4.0 \\
\hline Signed out against medical advice & 0.4 & 0.9 & 0.4 & 0.4 \\
\hline Transferred to acute care & 3.0 & 5.9 & 9.5 & 2.6 \\
\hline Transferred to long-term care & 6.6 & 26.7 & 24.0 & 5.6 \\
\hline Transferred to other facility & 0.3 & 2.5 & 0.7 & 0.2 \\
\hline Did not return from a pass & 0.01 & 0 & 0 & 0.01 \\
\hline Total direct costs over study period, \$ & 936671040 & 35462016 & 336992448 & 564216576 \\
\hline$\%$ of total costs & 100.0 & 3.8 & 36.0 & 60.2 \\
\hline Direct cost per patient, $\$$, median (IQR) & $3598(1485-8864)$ & $136558(98514-174328)$ & 52544 (40 138-75 305) & $3291(1361-7581)$ \\
\hline \multicolumn{5}{|l|}{ Resource utilization, \% of direct inpatient spending } \\
\hline Endoscopy & 0.4 & 0.3 & 0.3 & 0.4 \\
\hline Food services & 2.6 & 2.7 & 2.6 & 2.6 \\
\hline Health professional services & 5.0 & 7.2 & 7.6 & 3.3 \\
\hline Imaging & 3.1 & 3.0 & 3.2 & 3.1 \\
\hline Laboratory & 7.4 & 5.8 & 5.6 & 8.6 \\
\hline Nursing & 45.4 & 44.9 & 39.8 & 48.8 \\
\hline Operating room & 8.2 & 2.6 & 3.0 & 11.6 \\
\hline Surgical implants & 4.4 & 2.1 & 2.0 & 5.9 \\
\hline Pharmacy & 7.1 & 10.5 & 8.8 & 5.8 \\
\hline Post-anesthesia care unit & 2.0 & 0.8 & 0.8 & 2.9 \\
\hline ICU & 14.4 & 20.1 & 26.3 & 7.0 \\
\hline \multicolumn{5}{|c|}{$\begin{array}{l}\text { Note: ICU = intensive care unit, IQR = interquartile range. } \\
\text { *Persistently high cost = costs were in top } 5 \% \text { of cumulative direct costs in } 2 \text { or more of the study years; episodic high cost = costs were in top } 5 \% \text { in only } 1 \text { of the study years; } \\
\text { non-high cost = costs were in the bottom } 95 \% \text { in all study years (includes patients with no events in a fiscal year). } \\
\text { †Unless stated otherwise. } \\
\text { †Among patients with an ICU admission. } \\
\text { §Among patients with a hospital admission that had an alternate level of care component. } \\
\text { qAmong patients eligible for hospital readmission (excludes patients who died in hospital before discharge). }\end{array}$} \\
\hline
\end{tabular}


Previous studies implemented cost-based or diagnosisbased methods to identify patients at greatest risk of future high costs. ${ }^{8}, 11-13,23$ A common finding was that a substantial number of individuals were misclassified as high-risk in prospective years. This random component, where high-cost patients move in and out of different cost states, not only limits the predictive ability of these models but also makes it difficult to identify those who would benefit from specialized care management. We found that most of the patients in our study had no hospital admissions in the year following their index admission, regardless of their initial cost state. Furthermore, only a small number either remained in the same high-cost state or transitioned to a higher cost state in subsequent years. These findings differ from results of previous studies, which showed that more than half of high-cost patients remained in the high-cost group in the following year. ${ }^{3,6,9}$ This difference is likely because the previous studies analyzed data from Medicare and Medicaid populations, a group at risk of increased health care use and poor outcomes. Furthermore, they did not discriminate between high-cost patients using expensive but appropriate care and those for whom case management outside of the hospital setting may have reduced future costs.

Previous work has suggested that older patients are more likely than younger patients to be in the persistently high-cost group. ${ }^{3-7,9,24-26}$ Although risk of hospital admission and medical costs are known to increase with age, ${ }^{27}$ costs for long-term care are a substantial driver of health expenditures in this group and

Table 3: Measures of additional health care use in the year before and the year after the index hospital admission, by cost status ${ }^{\star}$

\begin{tabular}{|c|c|c|c|c|}
\hline \multirow[b]{2}{*}{ Variable } & \multicolumn{4}{|c|}{ Cost status; no. of visits, median (IQR) } \\
\hline & $\begin{array}{c}\text { All } \\
n=100178\end{array}$ & $\begin{array}{l}\text { Persistently high cost } \\
\qquad n=236\end{array}$ & $\begin{array}{l}\text { Episodic high cost } \\
\qquad n=5062\end{array}$ & $\begin{array}{c}\text { Non-high cost } \\
n=94880\end{array}$ \\
\hline \multicolumn{5}{|l|}{ Year before index admission } \\
\hline Outpatient physician visits & $1(0-5)$ & $6(1-12)$ & $2(0-7)$ & $1(0-5)$ \\
\hline Emergency department visits & $0(0-1)$ & $1(0-2)$ & $0(0-1)$ & $0(0-1)$ \\
\hline Medical daycare visits & $0(0-0)$ & $0(0-0)$ & $0(0-0)$ & $0(0-0)$ \\
\hline Surgical visits & $0(0-0)$ & $0(0-1)$ & $0(0-0)$ & $0(0-0)$ \\
\hline \multicolumn{5}{|l|}{ Year after index admission } \\
\hline Outpatient physician visits & $1(0-5)$ & $12(6-22)$ & $4(0-12)$ & $1(0-5)$ \\
\hline Emergency department visits & $0(0-0)$ & $3(1-6)$ & $1(0-2)$ & $0(0-0)$ \\
\hline Medical daycare visits & $0(0-0)$ & $0(0-1)$ & $0(0-0)$ & $0(0-0)$ \\
\hline Surgical visits & $0(0-0)$ & $0(0-1)$ & $0(0-0)$ & $0(0-0)$ \\
\hline
\end{tabular}

Table 4: Transition matrix showing average probability of changing cost status within 1 year*

\begin{tabular}{|c|c|c|c|c|c|c|c|c|}
\hline \multirow[b]{2}{*}{ Current cost status } & \multicolumn{8}{|c|}{ Future cost status } \\
\hline & $\begin{array}{l}\text { Top 5\% } \\
\text { (alive) }\end{array}$ & $\begin{array}{l}\text { Top 5\% } \\
\text { (died) }\end{array}$ & $\begin{array}{c}\text { Top } 5 \%-10 \% \\
\text { (alive) }\end{array}$ & $\begin{array}{c}\text { Top } 5 \%-10 \% \\
\text { (died) }\end{array}$ & $\begin{array}{l}\text { Bottom } 90 \% \\
\text { (alive) }\end{array}$ & $\begin{array}{l}\text { Bottom } 90 \% \\
\text { (died) }\end{array}$ & $\begin{array}{l}\text { No cost } \\
\text { (alive) } \dagger\end{array}$ & $\begin{array}{l}\text { No cost } \\
\text { (died) }\end{array}$ \\
\hline Top 5\% (alive) & 5.7 & 1.7 & 3.0 & 0.9 & 15.2 & 2.7 & 70.9 & 0 \\
\hline Top 5\% (died) & 0 & 0 & 0 & 0 & 0 & 0 & 0 & 100 \\
\hline Top 5\%-10\% (alive) & 2.6 & 0.9 & 2.7 & 0.8 & 14.5 & 2.1 & 76.5 & 0 \\
\hline Top 5\%-10\% (died) & 0 & 0 & 0 & 0 & 0 & 0 & 0 & 100 \\
\hline Bottom 90\% (alive) & 0.6 & 0.2 & 0.7 & 0.1 & 8.2 & 0.5 & 89.7 & 0 \\
\hline Bottom $90 \%$ (died) & 0 & 0 & 0 & 0 & 0 & 0 & 0 & 100 \\
\hline No cost (alive)† & 1.9 & 0.4 & 2.1 & 0.3 & 46.1 & 1.2 & 48.0 & 0 \\
\hline No cost (died) & 0 & 0 & 0 & 0 & 0 & 0 & 0 & 100 \\
\hline
\end{tabular}


by definition place a proportion of older patients in the persistently high-cost category. These patients are not likely the focus of specialized case management (despite their high-cost state), because their care setting is the most appropriate, albeit expensive. In future studies, costs should be broken down into the respective services to provide meaningful information on high-risk groups that remain at or move to higher cost states.

We found that almost $20 \%$ of patients in the persistently high-cost group had multiple admissions to an alternate level of care over time. Although this finding may suggest inefficiencies or difficulties within our health care system to effectively move high-risk patients out of the acute care setting, it can also be seen as an opportunity to improve our models of care. However, this will likely begin with an exploration of potential barriers that impede efficient transitions out of acute care and the various system, patient and social circumstances that result in multiple admissions to an alternate level of care. ${ }^{28}$

Improving outpatient management for high-cost patients, particularly those with chronic conditions known to drive health care spending, has also been identified as a priority within health care. Various outpatient interventions have been shown to reduce the risk of hospital readmission, and inpatient costs in turn, in the setting of specific chronic conditions. ${ }^{29-31}$ Whether these interventions can be put in place to reduce hospital spending for patients with medically complex conditions who have multiple comorbidities remains to be determined. Furthermore, it is difficult to determine whether the cost of implementing specialized case management programs for a small group of patients with complex medical needs would offset the current costs imposed on the health care system, decrease health care use in other facets of the health system and ultimately improve patient outcomes.

\section{Limitations}

Our study should be interpreted in light of its limitations. First, we did not assess spending outside of the hospital setting. Although inpatient spending makes up a large proportion of health care spending and is arguably the greatest area of focus for potential cost savings, there are likely high-cost groups in a number of areas outside of the acute care setting. Second, we did not capture deaths that occurred outside of the hospital setting. This would result in some misclassification of patients within the transition matrix and underestimate the total proportion of patients who died in the year following a hospital admission. However, the number of misclassified patients was likely small given that most patients die in a hospital setting. ${ }^{32}$ Finally, the study setting was limited to a single acute tertiary care hospital in Canada, and the findings may not be generalizable to other jurisdictions with variations in primary care delivery, capacity to care for patients within the community, and patient case-mix. Despite this limitation, our cost estimates are similar to those observed in other acute care facilities provincially. ${ }^{33}$

\section{Conclusion}

We found that hospital spending was often limited to a single year for most patients and that only a small proportion of patients remained in the high-cost group in subsequent years. These persistently high-cost patients are medically complex and often require expensive care. A greater understanding of the circumstances that result in persistent hospital spending is an area of future work. This may include an exploration of the potential barriers impeding efficient transition out of acute care and whether case management programs targeting this small group of patients with complex medical needs could offset current health care costs and ultimately improve patient outcomes.

\section{References}

1. National health expenditure trends, 1975 to 2012. Ottawa: Canadian Institute for Health Information; 2012. Available: https://secure.cihi.ca/free_products/ NHEXTrendsReport2012EN.pdf (accessed 2015 Feb. 3).

2. Berk ML, Monheit AC. The concentration of health care expenditures, revisited. Health Aff (Millwood) 2001;20:9-18.

3. Coughlin TA, Long SK. Health care spending and service use among highcost Medicaid beneficiaries, 2002-2004. Inquiry 2009-2010;46:405-17.

4. Forget EL, Deber R, Roos LL. Medical savings accounts: Will they reduce costs? CMA7 2002;167:143-7.

5. Joynt KE, Gawande AA, Orav EJ, et al. Contribution of preventable acute care spending to total spending for high-cost Medicare patients. FAMA 2013;309: 2572-8.

6. Riley GF. Long-term trends in the concentration of Medicare spending. Health Aff (Millwood) 2007;26:808-16.

7. Roos NP, Shapiro E, Tate R. Does a small minority of elderly account for a majority of health care expenditures? A sixteen-year perspective. Milbank $Q$ 1989;67:347-69.

8. Ash AS, Zhao Y, Ellis RP, et al. Finding future high-cost cases: comparing prior cost versus diagnosis-based methods. Health Serv Res 2001;36:194-206.

9. Freeborn DK, Pope CR, Mullooly JP, et al. Consistently high users of medical care among the elderly. Med Care 1990;28:527-40.

10. Greiner MA, Hammill BG, Fonarow GC, et al. Predicting costs among Medicare beneficiaries with heart failure. Am 7 Cardiol 2012;109:705-11.

11. Meenan RT, Goodman MJ, Fishman PA, et al. Using risk-adjustment models to identify high-cost risks. Med Care 2003;41:1301-12.

12. Meenan RT, O'Keeffe-Rosetti C, Hornbrook MC, et al. The sensitivity and specificity of forecasting high-cost users of medical care. Med Care 1999;37: 815-23.

13. Rosen AW, Wang F, Montez ME, et al. Identifying future high-healthcare users: exploring the value of diagnostic and prior utilization information. Dis Manag Health Outcomes 2005;13:117-27.

14. Zhao Y, Ash AS, Haughton J, et al. Identifying future high-cost cases through predictive modeling. Dis Manag Health Outcomes 2003;11:389-97.

15. Alexandre LM. High-cost patients in a fee-for-service medical plan. The case for earlier intervention. Med Care 1990;28:112-23.

16. Cohen $\mathrm{SB}, \mathrm{Yu}$ W. The persistence in the level of health expenditures over time: estimates for the U.S. population, 2002-2003. Rockville (MD): Agency for Healthcare Research and Quality; 2006. Available: http://meps.ahrq.gov/mepsweb/ data files/publications/st124/stat124.pdf (accessed 2015 Feb. 3).

17. Monheit AC. Persistence in health expenditures in the short run: prevalence and consequences. Med Care 2003;41(Suppl):III53-64.

18. Ontario case costing guide, version 9.0. Toronto: Data Standards Unit, Health Data Branch, Ministry of Health and Long-Term Care; 2014. Available upon request (info@occp.com).

19. Canadian Patient Cost Database technical document: MIS patient costing methodology, November 2011. Ottawa: Canadian Institute for Health Information; 2011. Available: www.cihi.ca/CIHI-ext-portal/pdf/internet/MIS_PATIENT_ COST_METH_EN (accessed 2015 Feb. 3).

20. Elixhauser A, Steiner C, Harris DR, et al. Comorbidity measures for use with administrative data. Med Care 1998;36:8-27.

21. van Walraven C, Jennings A, Quan $\mathrm{H}$, et al. A modification of the Elixhauser comorbidity measures into a point system for hospital death using administrative data. Med Care 2009;47:626-33

22. Olson ED, Anderson BS, Hardin JM. The analysis of health care coverage through transition matrices using a one factor model. 7 Data Sci 2010;8:619-30.

23. Lamers LM. Risk-adjusted capitation based on the Diagnostic Cost Group Model: an empirical evaluation with health survey information. Health Serv Res 1999;33:1727-44.

24. Anderson G, Knickman JR. Patterns of expenditures among high utilizers of medical care services. The experience of Medicare beneficiaries from 1974 to 1977. Med Care 1984;22:143-9.

25. McCall N, Wai HS. An analysis of the use of Medicare services by the continuously enrolled aged. Med Care 1983;21:567-85.

26. Roos NP, Shapiro E. The Manitoba longitudinal study on aging: preliminary 
findings on health care utilization by the elderly. Med Care 1981;19:644-57.

27. Alemayehu B, Warner KE. The lifetime distribution of health care costs. Health Serv Res 2004;39:627-42.

28. Walker D. Caring for our aging population and addressing alternate level of care. Report submitted to the Ministry of Health and Long-term Care. Toronto: Queen's Printer for Ontario; 2011. Available: www.health.gov.on.ca/en/common/ministry/ publications/reports/walker_2011/walker_2011.pdf (accessed 2015 Feb. 3).

29. Bourbeau J, Julien M, Maltais F, et al. Reduction of hospital utilization in patients with chronic obstructive pulmonary disease: a disease-specific selfmanagement intervention. Arch Intern Med 2003;163:585-91.

30. Moullec G, Lavoie KL, Rabhi K, et al. Effect of an integrated care programme on re-hospitalization of patients with chronic obstructive pulmonary disease. Respirology 2012;17:707-14.

31. Rice KL, Dewan N, Bloomfield HE, et al. Disease management program for chronic obstructive pulmonary disease: a randomized controlled trial. $A m \mathcal{7}$ Respir Crit Care Med 2010;182:890-6.

32. Health care use at the end of life in Atlantic Canada. Ottawa: Canadian Institute for Health Information; 2011. Available: https://secure.cihi.ca/free_products/ end_of_life_2011_en.pdf (accessed 2015 Feb. 3).

33. Wodchis WP. High cost users: driving value with a patient-centered bealth system. Toronto: Health System Performance Research Network; 2013. Available: www.crncc.ca/knowledge/events/pdf-healthyconnections2013/Wodchis.pdf (accessed 2015 Feb. 3).

Affiliations: Department of Clinical Epidemiology (Ronksley, Forster), Ottawa Hospital Research Institute; Department of Epidemiology and
Community Medicine (McKay, Kobewka), University of Ottawa; Department of Medicine (Kobewka, Mulpuru, Forster), University of Ottawa, Ottawa, Ont.

Contributors: Paul Ronksley was involved in the conception and design of the study and was responsible for conducting the analysis and interpreting the data. Jennifer McKay, Daniel Kobewka, Sunita Mulpuru and Alan Forster contributed to the study conception and design. Jennifer McKay and Alan Forster contributed to the analysis and interpretation of data. Paul Ronksley drafted the manuscript, and all of the authors revised it for important intellectual content. All of the authors approved the final version to be published and agreed to act as guarantors of the work.

Funding: No funding was received for this study.

Acknowledgements: Paul Ronksley is supported by a post-doctoral fellowship award from the Canadian Institutes of Health Research. Daniel Kobewka is supported by the University of Ottawa Patient Safety Fellowship. Sunita Mulpuru is supported by a Department of Medicine Research Fellowship through the University of Ottawa. Alan Forster is supported by a career salary award from the Department of Medicine at the University of Ottawa.

Supplemental information: For reviewer comments and the original submission of this manuscript, please see www.cmajopen.ca/content/3/1/ E111/suppl/DC1 